\title{
PUBLICAÇÕES DO GESTÃO PÚBLICA E CIDADANIA
}

A divulgação das iniciativas inovadoras empreendidas por governos subnacionais constitui um dos objetivos principais do Programa GESTÃO PÚBLICA E CIDADANIA e envolve, além da constituição de um banco de dados aberto a todos os interessados, a realização de pesquisas e estudos que contribuam para a identificação de elementos inovadores, de fatores facilitadores da inovação e de eventuais obstáculos à introdução de mudanças na administração püblica subnacional no Brasil.

Nossas publicações e fitas encontram-se disponíveis no programa e por meio da editora da FGV.

\section{PROGRAMA GESTÃO PÚBLICA E CIDADANIA}

\section{CADERNOS}

VOLUME 01 - A Administração Pública Brasileira Inovando a Forma de Governar: apresentação dos 629 programas inscritos no Ciclo de Premiação 1996 / Ricardo Ernesto Vasquez Beltrão (org.).

VOLUME 02 - Criação do Capital Social: o caso da Asmare / Pedro Jacobi e Marco Antonio Carvalho Teixeira.

VOLUME 03 - Desafio e Inovação em Políticas Públicas: programas para crianças e adolescentes em situação de risco / Laura Veiga, Bruno Lazarotti Diniz Costa e Carla Bronzo Ladeira Carneiro.

VOLUME 04 - Governo Local e Novas Formas de Provisão e Gestão de Serviços Públicos no Brasil / Marta Ferreira Santos Farah.

VOLUME 05 - Gestão Pública em Busca de Cidadania: experiências de inovação em Salvador / José Antônio Gomes de Pinho, Mercejane Santana e Sonia Cerqueira.

VOLUME 06 - Estudo Comparativo de Resultados Alcançados por Programas na Área de Saúde / Humberto Marques Filho

VOLUME 07 - Gestão Pública e Cidadania: metodologias participativas em ação / Fernando Guilherme Tenório e Jacob E. Rozenber

VOLUME 08 - A Administração Pública Brasileira Inovando a Forma de Governar: apresentação dos 297 programas inscritos no Ciclo de Premiação 1997 / Ricardo Ernesto Vasquez Beltrão (org.).

VOLUME 09 - Avaliação da Importância de Atributos de Projetos de Desenvolvimento Inovadores / Luis Roque Klering, Roberto Costa Fachin e Zilá Mesquita.

VOLUME 10 - Relatório sobre as Experiências Semifinalistas do Programa Gestão Pública e Cidadania - Ciclo de Premiação 1997 / Fernando Guilherme Tenório e Augusto P. G. Cunha.

VOLUME 11 - PROVE: uma experiência de implantação de microempresas agroindustriais / Humberto Marques Filho e Dilma Maria Guedes.

VOLUME 12 - A Administração Pública Brasileira Inovando a Forma de Governar: apresentação dos 631 programas inscritos no Ciclo de Premiação 1998 / Ricardo Ernesto Vasquez Beltrão, Carlos Eduardo Evangelisti Mauro e Patricia Laczynski (org.). 
VOLUME 13 - Programas para Crianças e Adolescentes em Situação de Risco: a complexidade do objeto e a dimensão institucional / Bruno Lazarotti Diniz Costa, Carla Bronzo Ladeira Carneiro e Carlos Aurélio Pimenta de Faria.

VOLUME 14 - Uma Releitura dos Programas Selecionados nos Ciclos de Premiação de 1996 e 1997 / Humberto Marques Filho e André Luiz Felisberto

VOLUME 15 - A Sociedade é Protagonista na Relação com o Estado? / Fernando Guilherme Tenório e Gylcilene Ribeiro Storino .

VOLUME 16 - A Administração pública brasileira inovando a forma de governar: apresentação dos 888 programas inscritos no Ciclo de Premiação 1999 - Patrícia Laczinski, Sabrina Addison Baracchini e Ricardo Ernesto Vasquez Beltrão (org.)

VOLUME 17 - The rights approach to subnational government: the experience of the public management and citizenship program - Peter Spink.

VOLUME 18 - Parcerias, novos arranjos institucionais e políticas públicas locais - Marta Ferreira Santos Farah.

VOLUME 19 - A Administração pública brasileira inovando a forma de governar: apresentação dos 946 programas inscritos no Ciclo de Premiação 2000 - Marta Ferreira Santos Farah, Patrícia Laczynski, Paulo Jábali Júnior, Odélio Rodarte Arouca Filho.

VOLUME 20 - O Governo Municipal no Brasil: construindo uma nova agenda política na década de 90 José Antônio Gomes de Pinho e Mercejane Wanderley Santana.

VOLUME 21 - A Administração Pública Brasileira Inovando a Forma de Governar: apresentação dos 727 programas inscritos no Ciclo de Premiação 2001 - Peter Spink, Patrícia Laczynski e Francine Rodarte Arouca (orgs)

\section{LIVROS}

20 Experiências de Gestão Pública e Cidadania (Ciclo de Premiação 1996) / Peter Spink e Roberta Clemente (org.).

20 Experiências de Gestão Pública e Cidadania (Ciclo de Premiação 1997) / Marta Ferreira Santos Farah, Nelson Luiz Nouvel Alessio e Luis Mario Fujiwara (org.).

20 Experiências de Gestão Pública e Cidadania (Ciclo de Premiação 1998) / Marta Ferreira Santos Farah, Nelson Luiz Nouvel Alessio e Luis Mario Fujiwara (org.).

Novas Experiências de Gestão Pública e Cidadania (Ciclo de Premiação 1999) / Marta Ferreira Santos Farah, Hélio Batista Barboza e Luis Mario Fujiwara (org.).

Histórias de um Brasil que funciona (Ciclo de Premiação 2000) / Marta Ferreira Santos Farah, Hélio Batista Barboza e Luis Mario Fujiwara (org.).

Histórias de um Brasil que Funciona (Ciclo de Premiação 2001) / SPINK, Peter, Hélio Batista Barboza (org) 


\section{FITAS DE VÍDEO}

Novos Caminhos para uma Gestão Pública com Cidadania. (1998) : Programa Gestão Pública e Cidadania Juliana Spink (coordenação).

Apresentando o Programa Gestão Pública e Cidadania. (2001) : Como funciona o Programa, e qual e a "filosofia" trabalho realizado.

Finalistas do Ciclo de 1999. (2001): Panorama dos programas finalistas do ano de 1999.

Construindo Cidadania. (2001) : Introdução ao Programa; a administração pública na ótica dos direitos humanos; cidadania política e cidadania social; tendências observadas nos programas inscritos; exemplos de projetos selecionados entre os finalistas de 2000; depoimentos: onde estamos na conquista da cidadania dentro do espaço público?

Combate à Pobreza na Gestão Pública. (2001) : Quadro de pobreza no Brasil; análise do conceito de pobreza; a importância das parcerias e alianças; programas de combate à pobreza e formação de parcerias reunidos no banco de dados; exemplos de projetos selecionados entre os finalistas de 2000; depoimentos: as experiências de parceria alteram a responsabilidade de governos na prestação de serviços?

\section{PROJETO ESPECIAL - PRÁTICAS E PÚBLICAS E POBREZA}

\section{LIVROS}

Estratégias Locais para Redução da Pobreza: Construindo a Cidadania (Relatório Final) - Ilka Camarotti e Peter Spink (org.).

Dez Experiências de Alianças na Redução da Pobreza - Ilka Camarotti e Peter Spink (org.).

Parcerias e Pobreza: Soluções Locais na Construção de Relações Sócio-Econômicas, vol. 1 - Ilka Camarotti e Peter Spink (org.).

Parcerias e Pobreza: Soluções Locais na Implementação de Políticas Sociais, vol. 2 - Ilka Camarotti e Peter Spink (org.)

Redução da Pobreza e Dinâmicas Locais - Ilka Camarotti e Peter Spink (org.)

Alianças na Redução da Pobreza: possibilidades e alcances. Resumo das experiências discutidas durante o Fórum realizado em Agosto 2001.

\section{FITA DE VIDEO}

Parcerias, Pobreza e Cidadania - Coordenação Juliana Spink.. 